\title{
Identifying the Substance Abuse Treatment Needs of Caregivers Involved with Child Welfare
}

\author{
Emmeline Chuang, PhD, \\ Graduate School of Public Health, San Diego State University, 5500 Campanile Dr. San Diego, \\ CA 92182-4162, Tel: (619)-594-6439, Fax: (619)-594-6112 \\ Rebecca Wells, PhD, \\ Gillings School of Global Public Health, University of North Carolina at Chapel Hill, Campus Box \\ 7411, 1104 McGavran-Greenberg Hall, Chapel Hill, NC 27599-7411, Tel: 919-966-7384 \\ John Bellettiere, MA, and \\ Graduate School of Public Health, San Diego State University, 5500 Campanile Dr. San Diego, \\ CA 92182-4162, Tel: 732-998-6581 \\ Theodore P. Cross, PhD \\ School of Social Work, University of Illinois, 1010 West Nevada St. Urbana, IL 61801 \\ Emmeline Chuang: echuang@mail.sdsu.edu; Rebecca Wells: rswells@email.unc.edu; John Bellettiere: \\ jobellettiere@projects.sdsu.edu; Theodore P.Cross: tpcross@illinois.edu
}

\begin{abstract}
Parental substance use significantly increases risk of child maltreatment, but is often underidentified by child protective services. This study examined how agency use of standardized substance use assessments and child welfare investigative caseworker education, experience, and caseload affected caseworkers' identification of parental substance abuse treatment needs. Data are from a national probability sample of permanent, primary caregivers involved with child protective services whose children initially remained at home and whose confidential responses on two validated instruments indicated harmful substance use or dependence. Investigative caseworkers reported use of a formal assessment in over two thirds of cases in which substance use was accurately identified. However, weighted logistic regression indicated that agency provision of standardized assessment instruments was not associated with caseworker identification of caregiver needs. Caseworkers were also less likely to identify substance abuse when their caseloads were high and when caregivers were fathers. Implications for agency practice are discussed.
\end{abstract}

\section{Keywords}

Caregivers; child welfare; substance use; investigation; assessment

\footnotetext{
(c) 2013 Elsevier Inc. All rights reserved.

Correspondence to: Emmeline Chuang, echuang@mail.sdsu . edu.

The authors report no competing interests.
}

Publisher's Disclaimer: This is a PDF file of an unedited manuscript that has been accepted for publication. As a service to our customers we are providing this early version of the manuscript. The manuscript will undergo copyediting, typesetting, and review of the resulting proof before it is published in its final citable form. Please note that during the production process errors may be discovered which could affect the content, and all legal disclaimers that apply to the journal pertain. 


\section{Introduction}

Parental substance use poses significant risks to family functioning and child well-being (Barnard \& McKeganey, 2004; Wells, 2009). Caregivers who misuse drugs and alcohol are more likely to engage in health risk behaviors and maltreat their children (Graves, 1995; Nelson, Saunders, \& Landsman, 1993; Ondersma, 2002). Children of substance users are more likely to experience emotional and behavioral problems (Ashman, Dawson, \& Panagiotides, 2008; Drabble, 2007; J. Stein, Leslie, \& Nyamathi, 2002; Wolock \& Magura, 1996) as well as develop their own substance use disorders in adolescence and early adulthood (Biederman, Faraone, Monuteaux, \& Feighner, 2000; Cortes, Fleming, Mason, \& Catalano, 2009). The detrimental effects of parental substance use on children have led to federal requirements that health care providers notify child protective service (CPS) agencies of substance-exposed newborns (Childrens Bureau, 2009; Huestis \& Choo, 2002). In addition, virtually all states have child protection statutes that identify child exposure to illegal drug activity in their homes or environment as a form of maltreatment (Young et al., 2009).

Involvement with Child Protective Services (CPS) represents an opportunity to connect families to needed health and social services. Such services may ameliorate problems that led to or exacerbated maltreatment. Families that use services identified in their child welfare case plans are less likely to experience short term maltreatment recurrence (DePanfilis \& Zuravin, 2002). When caregivers enter substance abuse treatment more quickly and complete at least one treatment episode, children who have been removed from the home spend fewer days in out-of-home care and are more likely to be reunified (Green, Rockhill, \& Furrer, 2007; B. Smith, 2003).

For child welfare caseworkers, the challenge of connecting substance involved families to appropriate services begins with accurately identifying needs. Factors such as mental health comorbidities and domestic violence complicate substance use identification, yet are common among the families served by CPS (Casanueva, Martin, \& Runyan, 2009; Choi \& Ryan, 2007; Taylor, Guterman, Lee, \& Rathouz, 2009). Fear of criminal charges and/or losing their children may also lead caregivers to deny or under-report substance use (Grekin et al., 2010; L. Stein \& Rogers, 2008). Although identifying substance abuse treatment needs typically necessitates effort beyond simply asking caregivers about substance use (Allen, Donohue, Sutton, Haderlie, \& LaPota, 2009; Griffin, 1991), child welfare caseworkers generally receive little to no training in how to recognize or assess such disorders (Hohman, Finnegan, \& Clapp, 2008; Hughes \& Rycus, 2007) and may fail to detect more subtle indicators of substance use, such as impaired social functioning or health problems associated with substance use (Dore, Doris, \& Wright, 1995). As a result, substance use disorders are often under-identified in the investigation or assessment process (Courtenay, 1991; Schroeder, Lemieux, \& Pogue, 2008). Analysis of a national sample of families subject to CPS maltreatment investigations or assessments between 1999-2000 (the first cohort of the National Survey of Child and Adolescent Well-Being or NSCAW) found that investigative caseworkers failed to identify $61 \%$ of caregivers meeting DSM-IV criteria for substance use disorders (Young, Boles, \& Otero, 2007).

The purpose of the current study is to examine factors affecting child welfare investigative caseworkers' ability to identify caregiver substance use disorders when present. Data are drawn from the second NSCAW cohort, which is comprised of a national sample of families investigated or assessed for child maltreatment between 2008 and 2009. Factors hypothesized to affect caseworker identification of caregiver substance abuse treatment needs include agency use of standardized substance use assessments as well as caseworker attributes such as education, job tenure, and caseload, which can affect caseworker skills 
and/or opportunity to detect substance abuse. Standardized substance abuse screening and assessment instruments can improve diagnosis of substance use disorders and aid in the development of appropriate treatment plans (Hiller, Belenko, Welsh, Zajac, \& Peters, 2011; Mdege \& Lang, 2011). Previous research has not examined how caseworker attributes affect identification of substance use. However, caseworker educational background has been shown to affect the types of services families receive (Olsen \& Holmes, 1982) as well as the length of time children spent in foster care (Ryan, Garnier, Zyphur, \& Zhai, 2006).

Similarly, aspects of caseworkers' work climate such as caseload can affect caseworkers' ability to employ best practices as well as caregivers' receipt of needed health and social services (Chuang, Wells, Green, \& Reiter, 2011; B. Smith \& Donovan, 2003). Given caseworkers' vital roles as brokers to health and social services, the effects of their experience and work climates on their ability to identify families' needs merit investigation.

\subsection{Investigation and assessment in child welfare}

When investigating families for alleged maltreatment, a caseworker must assess the danger posed by the child's current home environment and then propose a plan for ensuring child safety based on this appraisal (Shlonsky \& Wagner, 2005). Specific procedures vary across states and counties (D’Andrade, Austin, \& Benton, 2008; English \& Pecora, 1994). However, in all cases of substantiated maltreatment, investigative caseworkers must utilize information on the developmental, social, and ecological factors within each family to develop an individualized case plan for ensuring child safety (Hughes \& Rycus, 2007; M. Johnson et al., 2008). Since caregiver substance use affects both child safety and the case plan needed to prevent future maltreatment (Berger, Slack, Waldfogel, \& Bruch, 2010; Shlonsky \& Wagner, 2005), caseworkers' ability to identify caregiver substance use accurately is a critical part of this process.

While the need to identify and address substance use in maltreating families is longrecognized (Dore, et al., 1995), significant barriers impede this in practice. For example, most tools currently used in the child welfare investigation or assessment process focus on identifying individual or family factors associated with future harm to the child. While such tools can help caseworkers determine level of affecting risk to children, they do not provide guidance regarding families' needs, appropriate services, and individualized case planning (DePanfilis \& Zuravin, 2001; Gambrill \& Shlonsky, 2001; Shlonsky \& Wagner, 2005). In addition, most of these tools either do not directly address substance use or include it only as a single, uni-dimensional, and binary item (Magura, Moses, \& Jones, 1987; Marsh, Smith, \& Bruni, 2011; Olsen, Allen, \& Azzi-Lessing, 1996).

Structured substance abuse screens and assessments have been designed and validated in many other health and human service sectors (e.g. Knight, Sherritt, Shrier, Harris, \& Chang, 2002; McCann, Simpson, Ries, \& Roy-Bryne, 2000). However, the extent to which such tools are currently used in the child welfare investigation or assessment process is unknown. These tools can facilitate the systematic compilation, recording, and analysis of relevant information on families' substance use. Therefore, in the current study, we hypothesize that agency use of standardized substance abuse assessments in the investigation process will increase caseworker identification of caregiver substance use disorders.

Caseworkers' clinical judgment and ability to engage effectively with families may also affect identification of substance abuse (Anthony, Austin, \& Cormier, 2010; Shlonsky \& Wagner, 2005). Evidence suggests that many caseworkers lack the clinical competencies necessary to detect substance use (Hughes \& Rycus, 2007), and often use inappropriate communication styles when soliciting this information (Forrester, McCambridge, Waissbein, \& Rollnick, 2008; Googins, 1984). One aspect of child welfare caseworkers' background that may improve identification of substance use is training in social work. Although social 
work programs have not traditionally addressed substance use (Bush \& Sainz, 1997; Straussner \& Senreich, 2002), social work training emphasizes use of community resources (Scannapieco \& Connell-Corrick, 2003), and thus may help caseworkers refer caregivers more successfully for assessments conducted by behavioral health care providers. Prior research has also found that professionally trained social workers are better prepared to work with families with multiple needs and to develop plans for permanency, compared to workers without a social work degree (Albers, Reilly, \& Rittner, 1993; Dhooper, Royse, \& Wolfe, 1990; Ryan, et al., 2006). We therefore hypothesized that caseworkers with social work degrees would be more likely to identify caregiver substance abuse when present.

In addition, caseworkers may develop skills in addressing substance abuse through experience. Although no prior published studies have examined how caseworker experience affects identification of family needs, one study found improved permanence outcomes as caseworkers gained experience during their first year of practice (Shapiro, 1976).

Manifestations of substance use can be subtle, and eliciting candid information can be challenging. Both observational and communication skills are likely to evolve over time. Hence, despite the sparse prior evidence, we hypothesized that investigative caseworkers' years in child welfare would be positively associated with detection of caregiver substance use-related disorders.

Finally, caseworkers with excessive caseloads may overlook caregiver substance abuse because they are forced to conduct superficial investigations (B. Smith \& Donovan, 2003), particularly when cases are not immediately flagged as high priority in the referral process (DePanfilis \& Girvin, 2005). For example, higher caseloads have been associated with lower perceived efficacy among caseworkers, especially with regards to knowledge of clients' domestic environment and their ability to respond to client needs (King, Le Bas, \& Spooner, 2000). Worker caseload has also been shown to affect family engagement and program participation, especially among cases involving parental substance use (Littell \& Tajima, 2000). Thus, our final hypothesis was that investigative caseworker work load would be negatively associated with detection of caregivers' substance use-related disorders.

\section{Methods}

\subsection{Data}

The current study utilized data from the second cohort of families from the National Survey of Child and Adolescent Well-Being (NSCAW). NSCAW is the only national, longitudinal study of families who were subjects of child abuse or neglect investigations or assessments conducted by U.S. CPS agencies. NSCAW was funded by the Administration for Children and Families within the U.S. Department of Health and Human Services, with field data collection carried out by RTI International (Dowd et al., 2010). A complex sampling design involving two stages of stratification was utilized. States requiring CPS agency first contact of participants were excluded from the sampling frame. With the second cohort of families (NSCAW II), the first level of sample stratification consisted of 82 primary sampling units (PSUs) located within 30 states (Dolan, Smith, Casanueva, \& Ringeisen, 2011). Within these PSUs, children were sampled from all child welfare investigations or assessments that closed between February 2008 and April 2009.

Information on child welfare agency practices was obtained through interviews with child welfare agency directors. These interviews included an item asking whether or not the agency had used a standardized substance abuse assessment instrument in the investigation process. Detailed retrospective assessments of family context and well-being were collected through face-to-face interviews with current primary caregivers (either permanent or foster), children, and their investigative caseworkers. Interviews with investigative caseworkers and 
families were conducted between March 2008 and September 2009, and occurred on average approximately 4 months after the close of investigation. Permanent primary caregivers were defined as the adult "most knowledgeable" about the child who had coresided with the child for at least two months. In situations where multiple possible respondents met these criteria, a hierarchy of parent-child relationships frequently employed in studies of children and adolescents was used to select the caregiver respondent. This hierarchy delineates an order for respondent selection that focuses first on the mother, followed by the grandmother, father, and other relatives. More detailed information about these selection criteria are available elsewhere (Dowd, et al., 2010). Identified permanent, primary caregivers were administered a series of validated instruments regarding their substance use and mental health status via an Audio Computer-Assisted Self Interview program, a methodology known to increase reporting of unlawful, socially unacceptable, or other sensitive behaviors by increasing respondents' sense of confidentiality (Turner et al., 1998).

Investigative caseworkers were separately asked to provide information on their own background and demographics as well as their assessment of families' behavioral health service needs in the last 12 months. These interviews required caseworkers to access families' written case records (Dowd, et al., 2010). Each caseworker was only interviewed about one case for NSCAW.

\subsection{Sample}

The initial NSCAW II sample consisted of 5,873 families. Investigative caseworker interviews were completed for 5,091 of these cases. In 3,533 of these 5,091 cases (69\%), permanent primary caregivers were interviewed rather than foster or other temporary caregivers. Given the current study's focus on factors affecting investigative caseworker identification of caregiver substance abuse problems when known to be present, we restricted the operational study sample to include only primary caregivers whose confidential, self-reported responses on two validated instruments (see below), indicated harmful use or dependence on alcohol and/or drugs. Application of this restriction reduced the sample to 442 caregivers within 80 public child welfare agencies. Listwise deletion for item missingness reduced the sample to 401 caregivers within 80 child welfare agencies.

Sampling weights within NSCAW account for differential selection probabilities as well as potential bias resulting from survey non-response and thus yield estimates that are nationally representative of families subject to child maltreatment investigations or assessments conducted by CPS living in states not requiring CPS agency first contact of sample members (Dowd, et al., 2010; Pfefferman, Skinner, Holmes, Goldstein, \& Rasbash, 1998). However, these weights do not account for item non-response. While levels of item non-response did not exceed $6 \%$ for any single item, weighted t-test comparisons indicated that caregivers in the final analytic sample differed from those excluded due to listwise deletion in other model variables in one area: investigative caseworkers' years in child welfare (6.58 years in the final analytic sample vs. 10.41 years in the excluded cases, $\mathrm{p}<0.05)$. When data are not considered missing completely at random (MCAR), multiple imputation can yield results that are less biased than complete case analysis (Allison, 2002). Therefore, we conducted multiple imputation using the multivariate normal imputation method within the Stata 12.0 MI module (StataCorp, 2011). A total of twenty imputations were used to reduce sampling error (Bodner, 2008). In order to preserve the relationship between dependent and independent variables, the dependent variable was included in the imputation procedure (von Hippel, 2007). However, the four cases with imputed values for the dependent variable were excluded from the final analysis, resulting in a final analytic sample of 438 cases. As shown in Table 1, weighted t-tests following imputation did not reveal any statistically significant differences between imputed and unimputed variables in our sample. 


\subsection{Measures}

2.3.1. Harmful use or dependence on drugs and/or alcohol-Harmful use or dependence was identified based on permanent, primary caregivers' confidential, selfreported responses on two validated instruments, the Alcohol Use Disorders Identification Test (AUDIT) and the Drug Abuse Screening Test (DAST-20). The AUDIT is a 10-item instrument developed by the World Health Organization (WHO) for identifying risky or harmful alcohol consumption as well as alcohol dependence and abuse (Babor, HigginsBiddle, Saunders, \& Monteiro, 2001); items assess the amount and frequency of alcohol intake (items 1-3) as well as the adverse consequences associated with drinking (items 410). The psychometric properties of the AUDIT have been established across a broad range of samples and settings, with reliability ranging from 0.75 to 0.97 , sensitivity ranging from 0.73 to 0.94 , and specificity ranging from 0.79 to 0.94 when a cutoff score of 5 is used (Berner, Kriston, Bentele, \& Harter, 2007; Meneses-Gaya, Zuardi, Loureiro, \& Crippa, 2009; Reinert \& Allen, 2007); this cutoff score is considered optimal for the detection of hazardous drinking in women and can also be used to detect at-risk drinking in men (Reinert \& Allen, 2007; Rumpf, Hapke, Meyer, \& John, 2002).

The DAST-20 is a 20-item instrument designed to measure problematic substance use that is frequently used for clinical screening and in treatment or evaluation research (Skinner \& Goldberg, 1986). Responses to the DAST-20 are given as binary (yes/no) items. Psychometric properties of the DAST-20 have also been established, with internal consistency ranging from 0.74 to 0.92 , sensitivity of $74 \%$, specificity of $83 \%$, and a hit rate of $81 \%$ when a cut-off score of 6 or higher is used (Cocco \& Carey, 1998; Yudko, Lozhkina, $\&$ Fouts, 2007).

Consistent with these guidelines, in the current study, we operationalized permanent, primary caregivers as meeting criteria for harmful use or dependence when their AUDIT scores were 5 or higher or their DAST-20 scores were 6 or higher.

\subsubsection{Identification of caregiver substance abuse treatment needs-}

Investigative caseworkers' identification of caregiver substance abuse treatment needs was operationalized as a dichotomous variable, set to 1 if the investigative caseworker indicated that the permanent primary caregiver needed services for a drug or alcohol problem and 0 if the caseworker did not so indicate.

\subsubsection{Agency use of standardized substance abuse assessments-Child}

welfare agency use of standardized substance abuse assessments was indicated by a dichotomous variable, set $=1$ if the director responded yes to a question asking whether the child welfare agency used a standardized substance abuse assessment during the investigation process and set to 0 if the agency director responded no.

2.3.4. Caseworker education, experience, and caseload-Investigative caseworker education was indicated by whether the caseworker's highest degree was a bachelor's or less (referent), Bachelor of Social Work (BSW); Master of Social Work (MSW), or other graduate degree. Although some prior research has focused exclusively on the effects of MSWs (Ryan, et al., 2006), other have asserted that bachelors programs in social work should also inculcate child welfare workers in values conducive to more effective practice (Scannapieco \& Connell-Corrick, 2003). By including separate measures of MSW and BSW, respectively, we allowed for tests of the effects of each degree. Caseworker experience was operationalized as the number of years the caseworker had worked in child welfare, and caseload was indicated by the average number of new investigations per month 
assigned to the caseworker over the last 3 months. Each of these measures was based on caseworker self-report.

2.3.5. Control variables-We also controlled for several other factors that might affect caseworker ability to identify caregiver substance abuse, including the primary type of alleged maltreatment (neglect, physical abuse, sexual abuse, substance abuse or exposure, domestic violence, or other); whether the child was reported for more than one type of alleged maltreatment; child age in years; caregiver African American, Hispanic, or other minority race/ethnicity (Inclan \& Hernandez, 1992; Levinson \& Straussner, 1978); and whether the permanent primary caregiver was the child's biological mother, father, or had another type of biological or functional relationship with the child.

\subsection{Analyses}

NSCAW data have a hierarchical structure, with families and caseworkers nested within child welfare agencies. In initial analyses, a fully unconditional random effects model indicated significant variation across child welfare agencies in caseworker identification of caregiver substance abuse treatment needs, with an intraclass correlation coefficient of $9 \%$. However, power considerations resulting from the dichotomous nature of the dependent variable and the relatively modest number of level- 2 units ( 80 child welfare agencies) with an average group membership of only 6 cases per agency precluded the use of multilevel analyses (Maas \& Hox, 2004; Moineddin, Matheson, \& Glazier, 2007; Raudenbush \& Bryk, 2002). Consequently, we conducted a single-level logistic regression model using the Stata 12.0 -svy- module (StataCorp, 2011), which accounts for the complex survey design of the data, accommodating probability weights and stratification as well as correlations in outcomes across families served by the same child welfare agencies. The post-hoc adjustment to standard errors used in the -svy- module is similar to that used by the robust standard error procedure, differing only by a constant multiplier (DeLeeuw \& Meijer, 2008; L. P. StataCorp, 2005).

Phi and biserial correlations between independent variables were all less than 0.4 and variance inflation factors (VIF) $<2.5$, below the threshold at which multicollinearity may be a concern in logistic regression (Allison, 1999). Statistical power analyses were conducted using Optimal Design to accommodate the clustering of individuals within child welfare agencies (Spybrook, Raudenbush, Liu, Congdon, \& Martinez, 2008). Results indicated an $80 \%$ likelihood of detecting medium-size ( 0.48 or higher) effects for agency use of standardized substance use assessments and small effect sizes ( $\sim .25$ or higher) for all other covariates in the model. Comparison of imputed and unimputed model results yielded no significant differences in the pattern of results; therefore, only the imputed results are provided below. This secondary data analysis was approved by the Institutional Review Board at the lead author's home institution. The original data collection was approved by an Institutional Review Board at RTI International.

\section{Results}

Of the permanent, primary caregivers in the NSCAW II cohort whose children were initially placed in-home, $12.5 \%$ (442 of 3,533) had AUDIT and/or DAST scores indicating harmful use or dependence on alcohol and/or other drugs; our final analytic sample was comprised of these caregivers. As shown in Table 1, investigative caseworkers identified the presence of substance abuse treatment needs in approximately $41 \%$ of the caregivers in our sample. Approximately a third (33\%) of directors reported agency use of a standardized substance abuse assessment instrument during the investigation or assessment process. 
Individual caseworker responses (not shown) confirmed the relatively low use of such instruments in frontline practice: less than a third (27\%) of caregivers in the sample were formally screened or assessed for substance use disorders. However, of the cases in which caregiver substance use was identified by caseworkers, over two thirds $(68 \%)$ received a formal substance use assessment. We initially considered using each investigative caseworker's report of whether a standardized substance abuse instrument was administered during investigation. However, very high correlations between caseworker report of substance abuse and of having used a formal assessment $(\Phi=0.91, \mathrm{p}<0.01)$ suggested that caseworkers might be using these instruments to confirm suspected treatment need rather than identify otherwise undetected need. We therefore chose to retain agency use of standardized instruments to screen or assess caregiver substance use disorders as exogenous to the dynamics of any particular case.

About a quarter (27\%) of investigative caseworkers had a Bachelor of Social Work. Close to a quarter of caseworkers had either a Master of Social Work (15\%) or other graduate degree (9\%). On average, caseworkers reported having worked 7 years in child welfare and being assigned 13 new investigations each month.

For $27 \%$ of the children in our sample, the most serious type of alleged maltreatment was neglect (i.e., failure to provide for the child's physical needs and/or lack of supervision). Other types of alleged maltreatment included physical abuse (19\%), sexual abuse (6\%), substance abuse or exposure (27\%), and domestic violence (6\%). The remaining $15 \%$ of children in our sample either experienced another type of maltreatment such as exploitation or legal maltreatment or were involved with the child welfare system for another reason (e.g., only way to get needed services for the family). Most children (61\%) were only reported for one type of alleged maltreatment; of the 150 cases reported for more than one type of maltreatment, 102 (68\%) included alleged substance abuse or exposure. Children's average age was 8.4 years. Almost half of the primary permanent caregivers of these children were racial/ethnic minorities: $12 \%$ were African-American, 23\% Hispanic, and $11 \%$ other minority status (Native Indian, Native Alaskan, Hawaiian or Pacific Islander, etc.). The vast majority ( $81 \%$ ) of permanent, primary caregivers were biological mothers; approximately $16 \%$ were biological fathers and only $3 \%$ had a different type of biological or functional relationship to the child. For the majority of cases in our sample (63\%), the permanent primary caregiver was the only adult in the household responsible for the child's health, education, and well-being.

Table 2 shows the multiple logistic regression results. Child welfare agency use of standardized substance use assessment tools did not significantly affect caseworker identification of caregiver substance abuse treatment needs. Caseworker attributes such as education and experience also had no effect. However, investigative caseworkers were less likely to identify caregiver substance abuse treatment needs when their caseloads were high $(\mathrm{OR}=0.95, \mathrm{p}<0.05)$, when caregivers were biological fathers rather than mothers $(\mathrm{OR}=$ $0.20, p<0.01$ ), and when the most serious type of alleged maltreatment was sexual abuse (OR $0.06, p<0.01$ ). Caseworkers were also more likely to identify caregiver substance abuse treatment needs when the primary type of alleged maltreatment was substance use $(\mathrm{OR}=3.69, \mathrm{p}<0.05)$.

\section{Discussion}

Substance abuse treatment professionals are well aware that the majority of individuals who need their services will not seek them, and this is certainly true for families engaged with child welfare (Libby et al., 2007). Identification of substance use disorders among caregivers involved with child welfare could facilitate their entry into treatment and thereby improve 
permanency and other outcomes for families (Green, et al., 2007; B. Smith, 2003). However, substance abuse treatment providers rely on child welfare agencies to identify caregivers with treatment needs. Prior research has documented low rates of child welfare caseworker identification of caregiver substance use (Courtenay, 1991; Dore, et al., 1995; Schroeder, et al., 2008). Consistent with this prior research, we found that investigative caseworkers in the current national sample accurately identified treatment needs for fewer than half of the caregivers whose AUDIT or DAST-20 scores indicated harmful use or dependence.

Although substance abuse screening and assessment tools have been described as critical to appropriate case planning (Dore, et al., 1995), only one third of child welfare agency directors reported use of such tools. Contrary to hypothesis, we also found that agency use of standardized substance abuse assessment tools was not significantly associated with caseworker identification of caregiver substance abuse treatment needs. This lack of association was unexpected, given that caseworkers reported use of a formal substance abuse assessment in over two thirds of cases in which caregiver substance use was identified. Even when assessment tools can aid in clinical decision-making and case planning, it is possible that caseworkers may resist their use due to insufficient training in how to administer them, perceived burden given high caseloads, and/or shifting and competing agency priorities (Hughes \& Rycus, 2007; Rycus \& Hughes, 1998). Some caseworkers also believe that standardized instruments contradict fundamental social work principles of relationship, empathy, and respect (Grove \& Meehl, 1996; W. Johnson, 1996). In these situations, agency director reports of agency policy may not reflect the reality of all caseworkers' practices (B. Smith \& Mogro-Wilson, 2007). Further research is needed to better determine when standardized substance abuse assessments are most useful and how to support their use in those instances.

The negative associations between caseworker caseload and identification of needs also warrant attention, particularly given evidence that high caseloads can also increase caseworker burnout and result in organizational conditions likely to compromise casework practices beyond identification of need (Drake \& Yamada, 1996; Jayaratne \& Chess, 1984; B. Smith \& Donovan, 2003). Standards set by national professional associations and accrediting bodies such as Child Welfare League of America and the Council on Accreditation recommend that investigative caseworkers be assigned an average of 12 and a maximum of 15 initial assessments of investigations per month per worker (Child Welfare League of America, 1999). In our sample, the average caseload was 13 per month, with approximately $25 \%$ of caseworkers reporting average caseloads higher than the recommended maximum of 15 . Since constrained resources make it difficult if not impossible for administrators to reduce caseload, these findings highlight practical challenges to improving caseworker identification of caregiver substance abuse treatment needs, regardless of how much education and/or other training they receive. Given the profound effects of caregiver substance abuse on children as well as additional costs for employers and society, future research might demonstrate the financial benefits of investing in child welfare capacity to address these behaviors.

One possible explanation for the lack of association between social work education and identification of caregiver substance abuse is that the communication styles and other microskills emphasized in social work training may be less useful in identifying needs than in facilitating subsequent caregiver engagement with recommended services (Hohman, et al., 2008). Detecting substance use is not traditionally emphasized in social work education or training (Bush \& Sainz, 1997; Straussner \& Senreich, 2002). However, without such training, caseworkers may fail to distinguish effects of substance misuse from symptoms of psychopathology, particularly in diverse groups (Inclan \& Hernandez, 1992; Levinson \& Straussner, 1978). 
Finally, in the current study, we found that caseworkers were less likely to identify substance use when the most serious type of alleged maltreatment was sexual abuse and when caregivers were the biological fathers of children. Perpetrators of sexual abuse, who are mostly men, were rarely the primary caregiver; caseworkers may have been less likely to identify substance abuse in primary caregivers who were not the alleged perpetrator. The findings related to fathers could be explained by different gender norms regarding acceptable levels of alcohol use or by caseworkers' lack of knowledge or experience working with fathers. Contributors to maltreatment potential as well as substance use patterns tend to differ by gender and age (Ammerman, Kolko, Kirisci, Blackson, \& Dawes, 1999; Brady \& Randall, 1999; Brecht, O’Brien, von Mayrhauser, \& Anglin, 2004). In addition, fathers traditionally have low levels of engagement with child welfare services. Interest in promoting paternal participation in child welfare services is a relatively recent phenomenon and caseworkers are still learning effective strategies for engaging fathers (Maxwell, Scourfield, Featherstone, Holland, \& Tolman, 2012; O’Donnell, Johnson, D'Aunno, \& Thornton, 2005). Consequently, child welfare caseworkers may be relatively inexperienced in identifying substance use disorders in fathers. Additional research is needed to determine the extent to which focused professional training affects caseworkers' ability to effectively identify treatment needs of these and other specific sub-groups of caregivers.

\subsection{Limitations}

Several limitations must be taken into consideration when interpreting findings from this study. First, the current study relied on caregiver responses to the AUDIT and DAST instruments to identify substance abuse treatment needs. While these instruments have been validated for use in the general population (Cocco \& Carey, 1998; El-Bassel et al., 1997; Rumpf, et al., 2002), with women and diverse racial/ethnic groups (Reinert \& Allen, 2007), and in settings where respondents may be motivated to conceal or distort their substance use behaviors (Skinner, 1982; Staley \& El-Guebaly, 1990; Yudko, et al., 2007), they have not been specifically tested with child welfare or minority populations. Contextual and/or cultural differences may affect the sensitivity and specificity of results and warrant use of different cut-points than those applied in this study. In addition, even though caregivers were contacted directly by NSCAW interviewers (rather than via the child welfare agency) and the use of ACASI technology improved protection of privacy by allowing caregivers to directly enter responses on a computer screen, it is likely that some caregivers did not accurately report their substance use. Consequently, it is possible that relying only on caregiver self-report may have resulted in an underestimate of the true prevalence of substance abuse needs in this population. Given the current study's focus on factors affecting caseworkers' ability to identify such needs when known to be present, this was not viewed as a major limitation.

Similar limitations in measures also constrained inferences from analyses. NSCAW's measure of agency use of standardized substance abuse assessments did not specify the types of instruments used. Lacking this information, we could not compare the reliability, sensitivity, or specificity of instruments used by child welfare agencies. We also could not determine whether some of these instruments may have been more effective than others at identifying substance use among families involved with CPS. NSCAW also did not ask caseworkers about training in the use of standardized substance abuse assessments, which could also have affected caseworker use of these tools (Osborne \& Benner, 2012). Future research should address both issues in more detail.

Two additional points are worth noting. First, the current study examined effective strategies for identifying substance use disorders among caregivers whose children were initially placed in-home after the investigation or assessment process, i.e. those perceived as being 
lower-risk ( $87 \%$ of the full sample). The focus on this subset of the overall child welfare population means that study results do not reflect the overall prevalence of harmful substance use or dependence among all families involved with the child welfare system. Parental substance use is significantly associated with both initial placement and subsequent re-entry into out-of-home care (Brook \& McDonald, 2009; Connell et al., 2009; Kimberlin, Anthony, \& Austin, 2009; D. Smith, Johnson, Pears, Fisher, \& DeGarmo, 2007); therefore, even though less than $13 \%$ of caregivers in our sample reported harmful use or dependence on drugs or alcohol, prevalence of such disorders is expected to be much higher among caregivers whose children were initially removed from home after investigation or assessment.

Finally, although early identification of substance abuse treatment needs is an important first step to improving child safety, permanency and family well-being, it does not address broader issues such as family engagement, local service availability, and service effectiveness that also affect whether individuals affected by substance use disorders access and successfully complete treatment (Oliveros \& Kaufman, 2011). A 1998 report by the U.S. Government Accountability Office estimated that only 50\% of caregivers required to receive substance abuse treatment as part of their child welfare service plans attend some treatment and even fewer ( 13\%) complete it (U.S. General Accounting Office, 1998). While the evidence base regarding effective substance abuse treatment has grown over the last decade (Ashley, Marsden, \& Brady, 2003; Greenfield et al., 2007; Osterling \& Austin, 2008), timely access to such services remains problematic for many families due to low parental engagement, funding issues, and burdensome eligibility requirements (Littell \& Tajima, 2000; Rockhill, Green, \& Newton-Curtis, 2008). Recent budget cuts have exacerbated these challenges and resulted in an overall decrease in services provided to children and families by state agencies (Childrens Bureau, 2011), even as the current economic climate increases families' need for such services and the demands placed on investigative caseworkers in responding to families in crisis. While the current study focused on factors improving identification of caregiver substance abuse treatment needs, additional strategies for improving caregiver engagement and access to both treatment and wraparound services are also necessary for addressing these needs in the long term.

\section{Acknowledgments}

Preparation of this paper was supported by the National Institute on Drug Abuse from Grant 1 R03 DA032863-01. Data in this paper are from the National Survey on Child and Adolescent Well-Being, which was developed under contract with the Administration on Children, Youth, and Families, U.S. Department of Health and Human Services (ACYF/DHHS). These data were provided by the National Data Archive on Child Abuse and Neglect. The information and opinions expressed herein reflect solely the position of the authors.

\section{References}

Albers E, Reilly T, Rittner B. Children in foster care: Possible factors affecting permanency planning. Child and Adolescent Social Work. 1993; 10:329-341.

Allen D, Donohue B, Sutton G, Haderlie M, LaPota H. Application of a standardized assessment methodology within the context of an evidence-based treatment for substance abuse and its associated problems. Behavior Modification. 2009; 33(5):618-654. [PubMed: 19864319]

Allison, PD. Logistic regression using the SAS system: Theory and application. Cary, NC: SAS Institute; 1999.

Allison, PD. Missing data. Thousand Oaks, CA: Sage Publications; 2002.

Ammerman R, Kolko DJ, Kirisci L, Blackson T, Dawes M. Child abuse potential in parents with histories of substance use disorders. Child Abuse \& Neglect. 1999; 23(12):1225-1238. [PubMed: 10626607] 
Anthony E, Austin M, Cormier D. Early detection of parental substance exposure and the role of child welfare. Children and Youth Services Review. 2010; 32:6-12.

Ashley OS, Marsden ME, Brady TM. Effectiveness of substance abuse treatment programming for women: A review. The American journal of drug and alcohol abuse. 2003; 29(1):19-53. [PubMed: 12731680]

Ashman S, Dawson G, Panagiotides H. Trajectories of maternal depression over 7 years: Relations with child psychophysiology and behavior and role of contextual risks. Development and Psychopathology. 2008; 20(1):55-77. [PubMed: 18211728]

Babor, TF.; Higgins-Biddle, JC.; Saunders, JB.; Monteiro, MG. The Alcohol Use Disorders Identification Test (AUDIT): Guidelines for use in primary care. 2. World Health Organization Department of Mental Health and Substance Dependence; 2001.

Barnard M, McKeganey N. The impact of parental problem drug use on children: What is the problem and what can be done to help? Addiction. 2004; 99(5):552-559. [PubMed: 15078229]

Berger L, Slack K, Waldfogel J, Bruch S. Caseworker-perceived caregiver substance abuse and Child Protective Service outcomes. Child Maltreatment. 2010; 15(3):199-210. [PubMed: 20460304]

Berner M, Kriston L, Bentele M, Harter M. The Alcohol Use Disorders Identification Test for detecting at-risk drinking: A systematic review and meta-analysis. Journal of Studies on Alcohol and Drugs. 2007; 68(3):461-473. [PubMed: 17446987]

Biederman J, Faraone S, Monuteaux M, Feighner J. Patterns of alcohol and drug use in adolescents can be predicted by parental substance use disorders. Pediatrics. 2000; 106(4):792-797. [PubMed: 11015524]

Bodner T. What improves with increased missing data imputations? Structural Equation Modeling. 2008; 15:651-675.

Brady K, Randall C. Gender differences in substance use disorders. Psychiatric Clinics of North America. 1999; 22(2):241-252. [PubMed: 10385931]

Brecht M, O'Brien A, von Mayrhauser C, Anglin MD. Methamphetamine use behaviors and gender differences. Addictive Behaviors. 2004; 29(1):89-106. [PubMed: 14667423]

Brook J, McDonald T. The impact of parental substance abuse on the stability of family reunifications from foster care. Children and Youth Services Review. 2009; 31:193-198.

Bush I, Sainz A. Preventing substance abuse from undermining permanency planning: Competencies at the intersection of culture, chemical dependency, and child welfare. Journal of Multicultural Social Work. 1997; 5(1/2):79-97.

Casanueva C, Martin S, Runyan D. Repeated reports for child maltreatment among intimate partner violence victims: Findings from the National Survey of Child and Adolescent Well-Being. Child Abuse \& Neglect. 2009; 33(2):84-93. [PubMed: 19285725]

Child Welfare League of America. CWLA Standards for Excellence for Services for Abused and Neglected Children and their Families. Washington DC: Child Welfare League of America, Inc; 1999.

Childrens Bureau. Parental drug use as child abuse: Summary of state laws. Washington DC: U.S. Department of Health and Human Services, Administration for Children and Families, Child Welfare Information Gateway; 2009. http://www.childwelfare.gov/systemwide/laws_policies/ statutes/drugexposed.pdf

Childrens Bureau. Child Maltreatment 2010. U.S. Department of Health and Human Services, Administration for Children and Families, Administration on Children, Youth, and Families, Children's Bureau; 2011. Available from http://www.acf.hhs.gov/programs/cb/stats_research/ index.htm\#can

Choi S, Ryan JP. Co-occurring problems for substance abusing mothers in child welfare: Matching services to improve reunification. Children and Youth Services Review. 2007; 29(11):1395-1410.

Chuang E, Wells R, Green S, Reiter K. Performance-based contracting and the moderating influence of caseworker role overload on service provision in child welfare. Administration in Social Work. 2011; 35(5):453-474. [PubMed: 22347768]

Cocco K, Carey K. Psychometric properties of the Drug Abuse Screening Test in psychiatric outpatients. Psychological Assessment. 1998; 10:408-414. 
Connell C, Vanderploeg J, Katz K, Caron C, Saunders L, Tebes J. Maltreatment following reunification: Predictors of subsequent Child Protective Services contact after children return home. Child Abuse \& Neglect. 2009; 33:218-228. [PubMed: 19327834]

Cortes R, Fleming C, Mason W, Catalano R. Risk factors linking maternal depressed mood to growth in adolescent substance use. Journal of Emotional and Behavioral Disorders. 2009; 17(1):49-64. [PubMed: 20160836]

Courtenay W. Are borderline clients underidentified in social agencies? Clinical Social Work Journal. 1991; 19(3):309-325.

D'Andrade A, Austin M, Benton A. Risk and safety assessment in child welfare: Instrument comparisons. Journal of Evidence-Based Social Work. 2008; 5(1/2):31-56. [PubMed: 19064444]

DeLeeuw, J.; Meijer, E. Handbook of Multilevel Analysis. Springer Verlag; 2008.

DePanfilis D, Girvin H. Investigating child maltreatment in out-of-home care: Barriers to effective decision-making. Children and Youth Services Review. 2005; 27:353-374.

DePanfilis D, Zuravin SJ. Assessing risk to determine the need for services. Children and Youth Services Review. 2001; 23(1):3-20.

DePanfilis D, Zuravin SJ. The effect of services on the recurrence of child maltreatment. Child abuse \& neglect. 2002; 26(2):187-205. [PubMed: 11933989]

Dhooper SS, Royse DD, Wolfe L. Does social work education make a difference? Social Work. 1990; 35(1):57. [PubMed: 2315763]

Dolan, M.; Smith, K.; Casanueva, C.; Ringeisen, H. OPRE REport \#2011-27a. Washington DC: Office of Planning, Research and Evaluation, Administration for Children and Families, U.S. Department of Health and Human Services; 2011. NSCAW II Baseline Report: Introduction to NSCAW II.

Dore MM, Doris J, Wright P. Identifying substance abuse in maltreating families: A child welfare challenge. Child Abuse \& Neglect. 1995; 19(5):531-543. [PubMed: 7664134]

Dowd, K.; Dolan, M.; Wallin, J.; Miller, KA.; Biemer, P.; Aragon-Logan, E.; Smith, K. National Survey of Child and Adolescent Well-Being II: Data File User's Manual Restricted Release Version. Ithaca, New York: National Data Archive on Child Abuse and Neglect; 2010.

Drabble L. Pathways to collaboration: Exploring values and collaborative practices between child welfare and substance abuse treatment fields. Child Maltreatment. 2007; 12:31-42. [PubMed: 17218646]

Drake B, Yamada G. A structural equation model of burnout and job exit among child protective services workers. Social Work Research. 1996; 20(3):180-187.

El-Bassel N, Schilling R, Schinke S, Orlandi M, Wei-Huei S, Back S. Assessing the utility of the Drug Abuse Screening Test in the workplace. Research on Social Work Practice. 1997; 7:99-114.

English D, Pecora P. Risk assessment as a practice method in Child Protective Services. Child Welfare. 1994; 73(5):451-473. [PubMed: 7924563]

Forrester D, McCambridge J, Waissbein C, Rollnick S. How do child and family social workers talk to parents about child welfare concerns? Child Abuse Review. 2008; 17(1):23-35.

Gambrill E, Shlonsky A. The need for comprehensive risk management systems in child welfare. Children and Youth Services Review. 2001; 23(1):79-107.

Googins B. Avoidance of the alcoholic client. Social Work. 1984; 2:161-166. [PubMed: 10265996]

Graves K. Risky sexual behavior and alcohol use among young adults: Results from a national survey. American Journal of Health Promotion. 1995; 10(1):27-36. [PubMed: 10155656]

Green BL, Rockhill A, Furrer C. Does substance abuse treatment make a difference for child welfare case outcomes? A statewide longitudinal analysis. Children and Youth Services Review. 2007; 29(4):460-473.

Greenfield S, Brooks A, Gordon S, Green C, Kropp F, McHugh R, Miele G. Substance abuse treatment entry, retention, and outcome in women: A review of the literature. Drug and Alcohol Dependence. 2007; 86(1):1-21. [PubMed: 16759822]

Grekin E, Svikis DS, Lam P, Connors V, Lebreton J, Streiner D, Ondersma S. Drug use during pregnancy: Validating the Drug Abuse Screening Test against physiological measures. Psychology of Addictive Behaviors. 2010; 24(4):719-723. [PubMed: 21198230] 
Griffin R. Assessing the drug-involved client. Families in Society. 1991; 72(2):87-94.

Grove W, Meehl P. Comparative efficiency of informal (subjective, impressionistic) and formal (mechanical, algorithmic) prediction procedures: The clinical-statistical controversy. Psychology, Public Policy, and Law. 1996; 2(2):293-323.

Hiller ML, Belenko S, Welsh W, Zajac G, Peters R. Screening and assessment: An evidence-based process for the management and care of adult drug-involved offenders. Handbook of Evidencebased Substance Abuse Treatment in Criminal Justice Settings. 2011; 11:45-62.

Hohman M, Finnegan D, Clapp J. A concurrent validation study of the Alcohol and Other Drug Identification (AODI) scale. Journal of Social Work Practice in the Addictions. 2008; 8(3):367379.

Huestis M, Choo R. Drug abuse's smallest victims: In utero drug exposure. Forensic Science International. 2002; 128:20-30. [PubMed: 12208017]

Hughes R, Rycus J. Issues in risk assessment in Child Protective Services. Journal of Public Child Welfare. 2007; 1(1):85-116.

Inclan J, Hernandez J. Cross-cultural perspectives and co-dependence: the case of poor Hispanics. American Journal of Orthopsychiatry. 1992; 62(2):244-255.

Jayaratne S, Chess WA. Job satisfaction, burnout, and turnover: A national study. Social Work. 1984; 29(5):448-453. [PubMed: 10268448]

Johnson, M.; Stone, S.; Lou, C.; Vu, C.; Ling, J.; Mizrahi, P.; Austin, M. Family assessment in child welfare services. 2008 .

Johnson W. Risk assessment resaerch: Progress and future directions. Protecting Children. 1996; 12(2):14-19.

Kimberlin S, Anthony E, Austin M. Re-entering foster care: Trends, evidence, and implications. Children and Youth Services Review. 2009; 31:471-481.

King R, Le Bas J, Spooner D. The impact of caseload on the personal efficacy of mental health case managers. Psychiatric Services. 2000; 51(3):364-368. [PubMed: 10686245]

Knight J, Sherritt L, Shrier L, Harris S, Chang G. Validity of the CRAFFT substance abuse screening test among adolescent clinic patients. Archives of Pediatrics and Adolescent Medicine. 2002; 156(6):607-614. [PubMed: 12038895]

Levinson V, Straussner S. Social workers as enablers in the treatment of alcoholics. Social Casework. 1978; 50(1):14-20.

Libby AM, Orton HD, Barth RP, Webb MB, Burns BJ, Wood PA, Spicer P. Mental Health and Substance Abuse Services to Parents of Children Involved with Child Welfare: A Study of Racial and Ethnic Differences for American Indian Parents. Administration and Policy in Mental Health and Mental Health Services Research. 2007; 34(2):150-159. [PubMed: 17066330]

Littell J, Tajima E. A multilevel model of client participation in intensive family preservation services. Social Service Review. 2000; 74:405-435.

Maas C, Hox J. Robustness issues in multilevel regression analysis. Statistica Neerlandica. 2004; 58:127-137.

Magura, S.; Moses, B.; Jones, M. Assessing risk and measuring change in families: The Family Risk Scales. Washington DC: Child Welfare League of America; 1987.

Marsh J, Smith B, Bruni M. Integrated substance abuse and child welfare services for women: A progress review. Children and Youth Services Review. 2011; 33(3):466-472. [PubMed: 21499525]

Maxwell N, Scourfield J, Featherstone B, Holland S, Tolman R. Engaging fathers in child welfare services: A narrative review of recent research evidence. Child and Family Social Work. 2012; 17:160-169.

McCann B, Simpson T, Ries R, Roy-Bryne P. Reliability and validity of screening instruments for drug and alcohol abuse in adults seeking evaluation for attention-deficit/hyperactivity disorder. American Journal on Addictions. 2000; 9(1):1-9. [PubMed: 10914288]

Mdege N, Lang J. Screening instruments for detecting illicit drug use/abuse that could be useful in general hospital wards: A systematic review. Addictive Behaviors. 2011; 36(12):1111-1119. [PubMed: 21821364] 
Meneses-Gaya C, Zuardi A, Loureiro S, Crippa J. Alcohol Use Disorders Identification Test (AUDIT): An updated systematic review of psychometric properties. Psychology \& Neuroscience. 2009; 2(1):83-97.

Moineddin R, Matheson F, Glazier R. A simulation study of sample size for multilevel logistic regression models. BMC Medical Research Methodology. 2007; 7:34-46. [PubMed: 17634107]

Nelson K, Saunders E, Landsman MJ. Chronic child neglect in perspective. Social Work. 1993; 38:661-671. [PubMed: 8256141]

O’Donnell J, Johnson W, D'Aunno LE, Thornton H. Fathers in child welfare: Caseworkers' perspectives. Child Welfare. 2005; 84(3):387-414. [PubMed: 15984170]

Oliveros A, Kaufman J. Addressing substance abuse treatment needs of parents involved with the child welfare system. Child Welfare. 2011; 90(1):25-41. [PubMed: 21950173]

Olsen LJ, Allen D, Azzi-Lessing L. Assessing risk in families affected by substance abuse. Child Abuse \& Neglect. 1996; 20(9):833-842. [PubMed: 8886467]

Olsen LJ, Holmes W. Educating child welfare workers: The effects of professional training on service delivery. Journal of Education for Social Work. 1982; 18(1):94-102.

Ondersma S. Predictors of neglect within low-SES families: The importance of substance abuse. American Journal of Orthopsychiatry. 2002; 72(3):383-391. [PubMed: 15792050]

Osborne V, Benner K. Utilizing screening, brief intervention, and referral to treatment: Teaching assessment of substance abuse. American Journal of Public Health. 2012; 102(7):e37-e38. [PubMed: 22594734]

Osterling K, Austin M. Substance abuse interventions for parents involved in the child welfare system: Evidence and implications. Journal of Evidence-Based Social Work. 2008; 5(1\&2):157-189. [PubMed: 19064448]

Pfefferman D, Skinner CJ, Holmes DJ, Goldstein H, Rasbash J. Weighting for unequal selection probabilities in multilevel models. Journal of the Royal Statistics Society, B. 1998; (60):123-140.

Raudenbush, SW.; Bryk, AS. Hierarchical linear models: Applications and data analysis methods. Thousand Oaks, CA: Sage; 2002.

Reinert D, Allen J. The Alcohol Use Disorders Identification Test (AUDIT): An update of research findings. Alcoholism: Clinical and Experimental Research. 2007; 31(2):185-199.

Rockhill A, Green BL, Newton-Curtis L. Accessing substance abuse treatment: Issues for parents involved with child welfare services. Child Welfare. 2008; 87(3):63-93. [PubMed: 19189805]

Rumpf H, Hapke U, Meyer C, John U. Screening for alcohol use disorders and at-risk drinking in the general population: Psychometric performance of three questionnaires. Alcohol and Alcoholism. 2002; 37(3):261-268. [PubMed: 12003915]

Ryan JP, Garnier P, Zyphur M, Zhai F. Investigating the effects of caseworker characteristics in child welfare. Children and Youth Services Review. 2006; 28(9):993-1006.

Rycus, J.; Hughes, R. Field guide to child welfare, I-IV. Washington DC: Child Welfare League of America; 1998.

Scannapieco M, Connell-Corrick K. Do collaborations with schools of social work make a difference for the field of child welfare? Journal of Human Behavior in the Social Environment. 2003; 7(1): $35-51$.

Schroeder J, Lemieux C, Pogue R. The collision of the Adoption and Safe Families Act and substance abuse: Research-based education and training priorities for child welfare professionals. Journal of Teaching in Social Work. 2008; 28(1/2):227-246.

Shapiro, D. Agencies and foster children. Columbia University Press; 1976.

Shlonsky A, Wagner D. The next step: Integrating actuarial risk assessment and clinical judgment into an evidence-based practice framework in CPS case management. Children and Youth Services Review. 2005; 27:409-427.

Skinner HA. The drug abuse screening test. Addictive Behaviors. 1982; 7(4):363-371. [PubMed: 7183189]

Skinner HA, Goldberg A. Evidence for a drug dependence syndrome among narcotic users. British Journal of Addictions. 1986; 81:479-484. 
Smith B. How parental drug use and drug treatment compliance are related to family reunification. Child Welfare. 2003; 82(3):335-365. [PubMed: 12769395]

Smith B, Donovan S. Child welfare practice in organizational and institutional context. Social Service Review. 2003; 77(4):541-563.

Smith B, Mogro-Wilson C. Multi-level influences on the practice of inter-agency collaboration in child welfare and substance abuse treatment. Children and Youth Services Review. 2007; 29(5):545556.

Smith D, Johnson A, Pears K, Fisher PA, DeGarmo DS. Child maltreatment and foster care: Unpacking the effects of prenatal and postnatal parental substance use. Child Maltreatment. 2007; 12(2):150-160. [PubMed: 17446568]

Spybrook J, Raudenbush SW, Liu X, Congdon R, Martinez A. Optimal Design for longitudinal and multilevel research: Documentation for the "Optimal Design" software. 2008

Staley D, El-Guebaly N. Psychometric properties of the Drug Abuse Screening Test in a psychiatric population. Addictive Behaviors. 1990; 15:257-264. [PubMed: 2378285]

StataCorp. . Stata Statistical Software: Release 12. College Station, TX: StataCorp LP; 2011.

StataCorp, L. P. Users Guide: Version 9.0. College Station, TX: Stata Press; 2005.

Stein J, Leslie M, Nyamathi A. Relative contributions of parent substance use and childhood maltreatment to chronic homelessness, depression, and substance abuse problems among homeless women: Mediating roles of self-esteem and abuse in adulthood. Child Abuse \& Neglect. 2002; 26:1011-1027. [PubMed: 12398858]

Stein, L.; Rogers, R. Denial and misreporting of substance abuse. Boston, MA: Guifford Press; 2008.

Straussner S, Senreich E. Educating social workers to work with individuals affected by substance use disorders. Substance Abuse. 2002; 23(S1):319-340. [PubMed: 23581004]

Taylor C, Guterman N, Lee S, Rathouz P. Intimate partner violence, maternal stress, nativity, and risk for maternal maltreatment of young children. American Journal of Public Health. 2009; 99(1): 175-183. [PubMed: 19008518]

Turner CF, Ku L, Rogers S, Lindberg L, Pleck J, Sonenstein F. Adolescent sexual behavior, drug use, and violence: Increased reporting with computer survey technology. Science. 1998; 280:867873. [PubMed: 9572724]

U.S. General Accounting Office. Foster care: Agencies face challenges securing stable homes for children of substance abusers. Washington, DC: 1998. GAO/HEHS-98-182

von Hippel P. Regression with missing Ys: An improved strategy for analyzing multiply imputed data. Sociological Methodology. 2007; 37(1):83-117.

Wells K. Substance abuse and child maltreatment. Pediatric Clinics of North America. 2009; 56(2): 345-362. [PubMed: 19358920]

Wolock I, Magura S. Parental substance abuse as a predictor of child maltreatment re-reports. Child Abuse \& Neglect. 1996; 20(12):1183-1193. [PubMed: 8985609]

Young N, Boles S, Otero C. Parental substance use disorders and child maltreatment: Overlaps, gaps, and opportunities. Child Maltreatment. 2007; 12(2):137-149. [PubMed: 17446567]

Young, N.; Gardner, S.; Otero, C.; Dennis, K.; Chang, R.; Earle, K.; Amatetti, S. Substance-exposed infants: State responses to the problem. Rockville, MD: Substance Abuse and Mental Health Services Administration; 2009. HHS Pub. No. (SMA) 09-4369

Yudko E, Lozhkina O, Fouts A. A comprehensive review of the psychometric properties of the Drug Abuse Screening Test. Journal of Substance Abuse Treatment. 2007; 32:189-198. [PubMed: 17306727] 


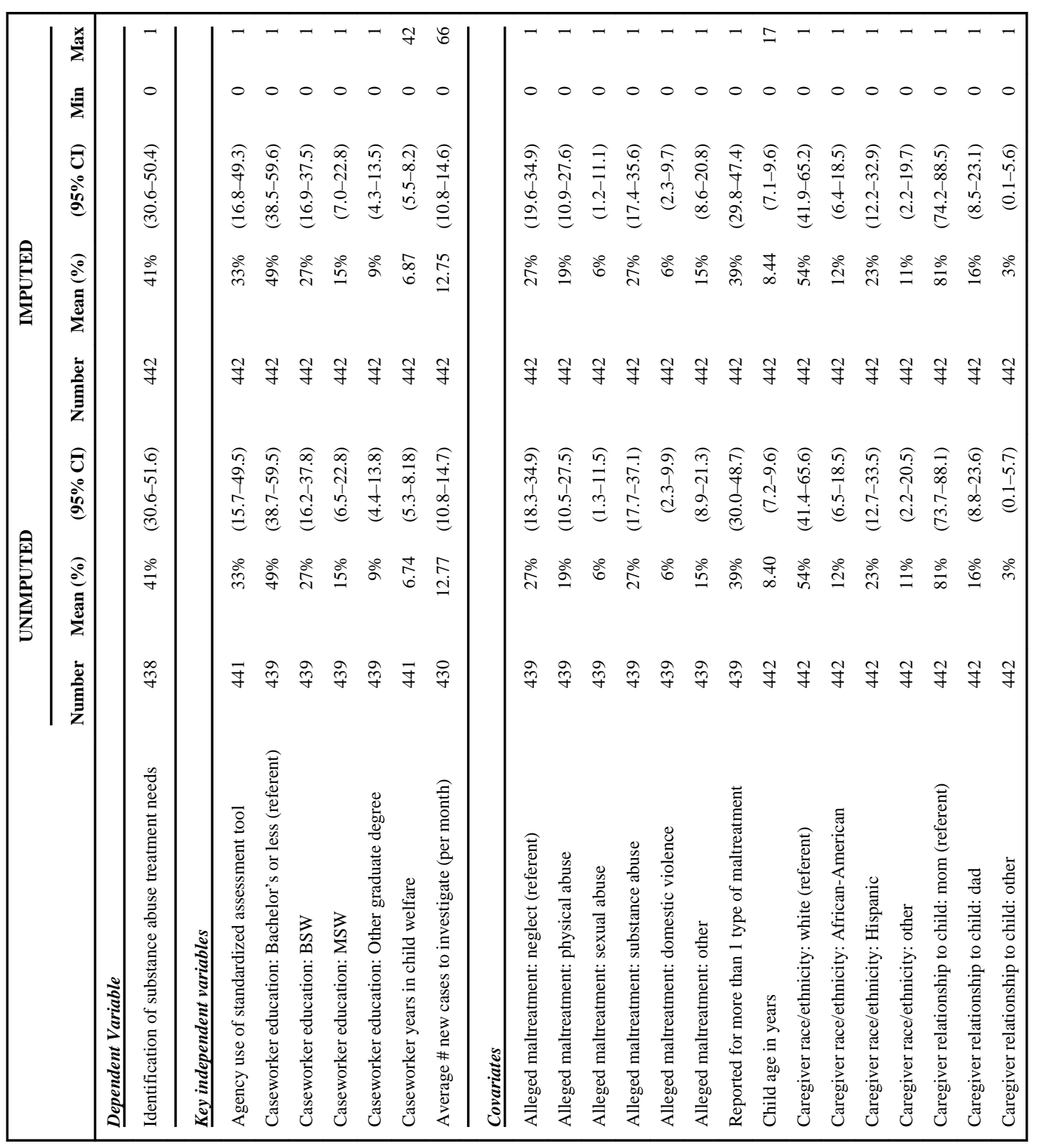

J Subst Abuse Treat. Author manuscript; available in PMC 2014 July 01. 


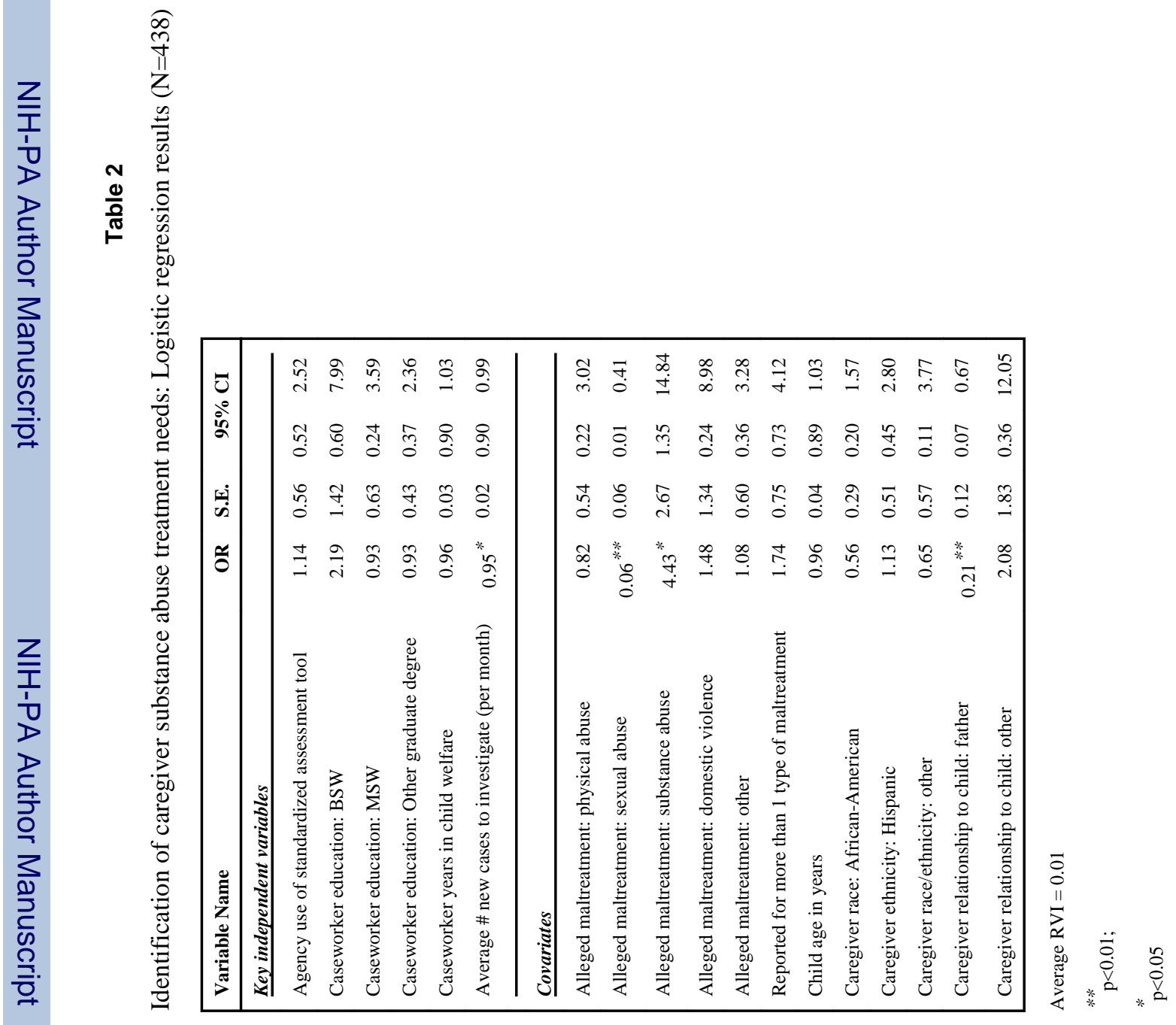

J Subst Abuse Treat. Author manuscript; available in PMC 2014 July 01. 